\title{
Climate of suspicion
}

\author{
With climate-change sceptics waiting to pounce on any scientific uncertainties, researchers need a \\ sophisticated strategy for communication.
}

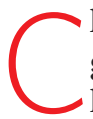
limate science, like any active field of research, has some major gaps in understanding (see page 284). Yet the political stakes have grown so high in this field, and the public discourse has become so heated, that climate researchers find it hard to talk openly about those gaps. The small coterie of individuals who deny humanity's influence on climate will try to use any perceived flaw in the evidence to discredit the entire picture. So how can researchers honestly describe the uncertainty in their work without it being misconstrued?

The e-mails leaked last year from the Climatic Research Unit of the University of East Anglia, UK, painted a picture of scientists grappling with this question, sometimes awkwardly. Some of the researchers' online discussion reflected a pervasive climate of suspicion - their sense that any findings they released to the public could and would be distorted by sceptics.

Over the years, the climate community has acquired some hard-won wisdom about treading this minefield. Perhaps the most important lesson is that researchers must be frank about their uncertainties and gaps in understanding - but without conveying the message that nothing is known or knowable. They must emphasize that - although many holes remain to be filled - there is little uncertainty about the overall conclusions: greenhouse-gas emissions are rising sharply, they are very likely to be the cause of recent global warming and precipitation changes, and the world is on a trajectory that will shoot far past $2^{\circ} \mathrm{C}$ of warming unless emissions are cut substantially. Researchers should also emphasize that cities and countries can begin to prepare for the effects of climate change through both mitigation and adaptation, even though they do not know the exact course of the changes.

The United Nations Intergovernmental Panel on Climate Change (IPCC) has taken this approach in its ongoing series of assessment reports, and it has done an admirable job of highlighting the impor- tant conclusions while acknowledging the caveats. It has made some errors, such as its use of questionable data about the retreat of Himalayan glaciers (see page 276), but these mistakes are exceedingly rare in reports that can total more than 1,000 pages, a testament to the IPCC's rigorous peer-review process.

No matter how evident climate change becomes, however, other factors will ultimately determine whether the public accepts the facts. Empirical evidence shows that people tend to react to reports on issues such as climate change according to their personal values (see page 296). Those who favour individualism over egali-
"The climateresearch community would do well to use a diverse set of voices when communicating with policy-makers and the public." tarianism are more likely to reject evidence of climate change and calls to restrict emissions. And the messenger matters perhaps just as much as the message. People have more trust in experts - and scientists - when they sense that the speaker shares their values. The climate-research community would thus do well to use a diverse set of voices, from different backgrounds, when communicating with policy-makers and the public. And scientists should be careful not to disparage those on the other side of a debate: a respectful tone makes it easier for people to change their minds if they share something in common with that other side.

As comforting as it may be to think that the best evidence will eventually convince the public on its own, climate scientists can no longer afford to make that naive assumption: people consider many factors beyond facts when making decisions. Even as climate science advances, it will be just as important to invest in research on how best to communicate environmental risks. Otherwise scientific knowledge will not have the role that it should in the shaping of public policy.

\section{Ten years of synergy}

Contributions to and from basic science are the part of synthetic biology that most deserves celebration.

t was an eclectic crowd of engineers, chemists, computer scientists - and, yes, a few biologists too - that gathered in Irvine, California, in November for the US National Academies Keck Futures Initiative discussion on the future needs of 'synthetic biology'. Their very definitions of the field were correspondingly divergent. But when pressed to focus on concrete examples, most discussion groups, at one point or another, pointed to a defining pair of experiments in tailored gene regulation that were published on 20 January 2000: the first synthetic biological oscillator - the 'repressilator' (M. B. Elowitz and
S. Leibler Nature 403, 335-338; 2000) - and a bistable generegulatory network, or 'toggle switch' (T. S. Gardner et al. Nature 403, $339-342 ; 2000)$. So those in the field may not agree on what it is, but they seem to know when it started.

Since then there have been ten years of vibrant interdisciplinary science, and much public discussion both in policy circles and in the media. No such fame could have been predicted at the outset. 'Synthetic biology' was not a common phrase, and many considered the gadgets merely practical extensions of genetic engineering at best, or irrelevant tricks at worst.

Both of those pioneering experiments transposed two great traditions of physics to biology: first, to understand something one must build it, and second, start from the simplest imaginable principles. These directives have set the basic-science agenda for synthetic biology: to design, and thus define, the minimal systems sufficient to 